Running head: SCREENING FOR ASD IN DAY-CARE CENTRES

Screening for Autism Spectrum Disorders in Flemish Day-care Centres with the Checklist for Early Signs of Developmental Disorders (CESDD)

Mieke Dereu, Petra Warreyn, Ruth Raymaekers, Mieke Meirsschaut, Griet Pattyn, Inge Schietecatte, and Herbert Roeyers

Ghent University 


\begin{abstract}
A new screening instrument for ASD was developed that can be filled out by child care workers: the Checklist for Early Signs of Developmental Disorders (CESDD). The predictive validity of the CESDD was evaluated in a population of 6808 children between 3 and 39 months attending day-care centres in Flanders. The CESDD had a sensitivity of .80 and a specificity of .94 . Based on the screening procedure used in this study, 41 children were diagnosed with ASD or got a working diagnosis of ASD. Thus, including child care workers' report on signs of ASD in screening procedures can help to identify cases of ASD at a young age.
\end{abstract}

Key words: Autism Spectrum Disorder, Screening, Early identification, Child care, Toddlers Mieke.Dereu@UGent.be 


\section{Screening for Autism Spectrum Disorders in Flemish Day-care Centres with the Checklist for Early Signs of Developmental Disorders (CESDD)}

Autism spectrum disorders (ASDs) is a term widely used to refer to a group of developmental disorders characterised by impairments in social interaction, communication and repetitive or restricted patterns of interests or behaviours (APA, 2000). Recent estimates of the prevalence of ASD range from 53 to 157 in 10000 children (Baron-Cohen et al., 2009; Gillberg, Cederlund, Lamberg, \& Zeijlon, 2006).

A diagnosis of ASD can be made accurately before the child is 3 years old (Stone et al., 1999). Although parents express their concerns about the development of their child during the first years of life, the diagnosis of ASD is commonly not confirmed until the child is somewhat older. Harrington, Patrick, Edwards, and Brand (2006) found in their survey that ages at diagnosis ranged from 14 months to 14 years. Moreover, Wiggins, Baio, and Rice (2006) showed that the average delay between mean age at first documented evaluation and mean age at first ASD diagnosis was 13 months. In Flanders, Renty and Roeyers (2006) found an average age of 69 months at diagnosis for children younger than 12 years with an average delay of 25 months between first recognition of symptoms and diagnosis of ASD. In this period on average three diagnostic centres were consulted.

The advantages of early identification of children with ASD are twofold. From a research point of view, early identification of children at risk for a diagnosis of ASD makes it possible to perform prospective studies into the developmental pathways of children with ASD (Reznick, Baranek, Reavis, Watson, \& Crais, 2007). From a clinical point of view, an early diagnosis of ASD can lead to early intervention, which may improve developmental outcomes in children with ASD (Eldevik et al., 2009). If intervention cannot begin in preschool years (i.e. to create important language and social-emotional experiences for the 
child), this may result in missed opportunities for optimal brain development (Branson, Vigil, \& Bingham, 2008). In addition, research has indicated that early diagnosis of the disorder can diminish familial stress, speed up referral to special educational programmes and influence family planning (Renty \& Roeyers, 2006). This has led to the current emphasis on early identification (Chakrabarti, Haubus, Dugmore, Orgill, \& Devine, 2005).

\section{Screening for ASD}

To detect children at high risk for ASD early on, Filipek and colleagues (1999) suggested the use of screening instruments for ASD suitable for infants and toddlers. In recent years, different screening instruments were developed to facilitate early identification of ASD at different ages.

A first screening instrument that can be used for screening in the general population, was developed by Baron-Cohen and colleagues: the Checklist for Autism in Toddlers (CHAT; Baron-Cohen, Allen, \& Gillberg, 1992; Baron-Cohen et al., 1996). This instrument was developed to identify 18 -month-olds at risk for autism. The checklist is administered by healthcare practitioners and includes questions that are asked to the parents as well as items that can be observed by primary healthcare practitioners. To calculate the sensitivity, specificity, and positive predictive value of the instrument, children were monitored until 7 years of age (Baird et al., 2000). This yielded a very good specificity of .98 , but a low sensitivity of .35 and a positive predictive value (PPV) of .08 for ASD, when screening in the general population.

The CHAT was later modified into a parent-report questionnaire by Robins, Fein, Barton, and Green (2001): the Modified Checklist for Autism in Toddlers (M-CHAT). Preliminary data revealed a very good sensitivity (.97) and specificity (.99) (Robins et al., 2001). However, these data were based on a rather limited sample of 1,122 children between 
18 and 30 months from a non-selected population and 171 children who were referred for early intervention services. More recent reports on the validation of the M-CHAT revealed a slightly lower sensitivity of .85 and specificity of .93 , but showed that the psychometric properties remain very promising. Sensitivity dropped because at rescreening at age 4 , six children were identified as possible misses (Dumont-Mathieu \& Fein, 2005).

Some recently developed screening instruments can be used to screen for ASD at even younger ages. The Early Screening for Autistic Traits Questionnaire (ESAT; Dietz, Swinkels, van Daalen, van Engeland, \& Buitelaar, 2006; Swinkels et al., 2006) was originally developed for 14 month-olds. When the ESAT was completed retrospectively by parents of children with ASD or ADHD, the ESAT detected 90.1\% of the children with ASD and 19\% of the children with ADHD (Swinkels et al., 2006). A population screening of 31,724 children between 13 and 23 months old detected 18 children with ASD. The PPV was .25 (Dietz et al., 2006). Groen, Swinkels, van der Gaag, and Buitelaar (2007) reported a sensitivity of .23 and a specificity of .99 for the ESAT. They calculated the sensitivity and specificity for the population screening of Dietz and colleagues (2006) based on the prevalence rate of ASD reported by Baird and colleagues. (2000).

Another parent report measure to identify very young children at risk for ASD is the First Year Inventory (FYI; Reznick et al., 2007) for 12 month-olds. A retrospective study with the FYI yielded good validity estimates. The sensitivity was .92 , the specificity .78 and the PPV .74 with the lowest cut-off point, i.e. at the $90^{\text {th }}$ percentile of the normative sample. Increasing this cut-off point to a total score corresponding with the $98^{\text {th }}$ percentile of the normative sample made the sensitivity decrease to .71 , but resulted in a better specificity of .89 and in a better PPV of .82 (Watson et al., 2007). An ongoing prospective study will further clarify the validity of this instrument in the general population. 


\section{Screening within a Childcare Setting}

The American Academy of Pediatrics (AAP) called in 2001 for all paediatricians to conduct developmental surveillance within their routine medical care (AAP, Committee on Children with Disabilities, 2001). Most countries have a certain form of developmental surveillance of very young children to detect developmental problems early on. However, this surveillance focuses primarily on general and sensorimotor development and less on the development of social-communicative skills. Additional specific screening for ASD is required (Dietz et al., 2006). Dosreis, Weiner, Johnson, and Newschaffer (2006) investigated the screening habits of paediatricians. They found that $82 \%$ regularly screened for general developmental delay, but only $8 \%$ screened for ASD because of time constraints and lack of familiarity with autism screening instruments. Moreover, the existing screening tools for ASD available to paediatricians have a low sensitivity (e.g. CHAT and ESAT). Therefore, additional sources for conducting screening can be helpful to promote early detection of the disorder in very young children.

One group of professionals is not yet included in the screening for ASD. In our opinion child care workers can help to identify children at risk for ASD. They are well educated in typical development and are encouraged to screen a child's development. Moreover, parents expect them to do so. They also have many opportunities to observe the children in the day-care centres and to compare the behaviour of a child with that of its peers. Others have also suggested the possible contribution of child care workers to the screening for ASD in young children (Branson et al., 2008).

Unfortunately, there are currently no screening instruments for ASD available that can be filled out by child care workers. Most existing screeners were developed to be easily filled out by parents (e.g. M-CHAT) or to be completed by healthcare professionals, for example in well-baby clinics (e.g. CHAT). To screen for ASD in infants and toddlers attending day-care 
centres in Flanders, a new screening instrument was developed that can be filled out by child care workers: the Checklist for Early Signs of Developmental Disorders (CESDD). By referring to developmental disorders, we wanted to avoid alarming parents at this early stage about the possibility that their child may have ASD. Informing them that their child was in need of further evaluation because it may have a developmental problem, seemed less frightening for parents. We chose to develop a new screening instrument rather than modifying an existing questionnaire because we wanted to construct one single instrument that can be used for the total age range within day-care centres in Flanders ( 3 months -3 years). Moreover, the instrument should incorporate as many as possible red flags of ASD for this total age range. None of the existing and validated instruments met these criteria.

The present paper focuses on the development of the CESDD, the screening procedure and the psychometric properties of the CESDD as a screener for ASD in a general population of infants and toddlers attending day-care centres.

\section{Method}

\section{Participants}

Day-care centres were recruited by contacting several organisations that coordinate the child care in Flanders. In total, 6808 children attending 70 different day-care centres were screened with the CESDD over the course of three years. This sample represented an estimated $34.48 \%$ of the children attending day-care centres in Flanders (Kind \& Gezin, 2008). The children were on average 16.70 months old $(S D=8.19$, range $3.00-38.90,52 \%$ male).

Of the total sample, 61 children had a diagnosis of a developmental disorder other than ASD. In 40 cases a diagnosis was already made prior to the screening procedure: 21 children had general developmental delay, 8 children had mental retardation, 5 children had a 
delay in motor development, 5 children had language delay and 1 child was diagnosed with a mixed receptive-expressive language disorder. Following the screening procedure, 4 children were diagnosed with mental retardation, 8 with general developmental delay and 9 children with language delay.

In total 27 children had a diagnosis of ASD. Seven of these children received the diagnosis prior to the screening procedure and for 20 children the diagnosis of ASD was made after referral following assessment at the university lab. Another 14 children are highly suspected of ASD but did not yet get the diagnosis. Seven of these children got a working diagnosis of ASD (cf. Charman \& Baird, 2002) in an autism clinic prior to the screening procedure, but await re-evaluation at an older age to reassert the diagnostic opinion. Another three children received a working diagnosis of ASD after referral through the screening procedure. Four children were highly suspected of having ASD after assessment at the university lab, however, the parents of these children chose to await the further development of their child and were not yet seen at an autism clinic with their child.

\section{Development of the Checklist for Early Signs of Developmental Disorders (CESDD)}

We performed a literature review on retrospective, prospective and home movie research on red flags of ASD in infants and toddlers (Adrien et al., 1991, 1993; Baranek, 1999; Eaves \& Ho, 2004; Gillberg et al., 1990; Gray \& Tonge, 2001; Lord, 1995; Mars, Mauk, \& Dorwick, 1998; Maestro, Casella, Milone, Muratori, \& Palacio-Espasa, 1999; Maestro et al., 2001; Osterling \& Dawson, 1994; Osterling, Dawson, \& Munson, 2002; Werner, Dawson, Osterling, \& Dinno, 2000; Wetherby et al., 2004; Wimpory, Hobson, Williams, \& Nash, 2000; Zwaigenbaum et al., 2005). Unpublished findings of home movie research of our own research group were also included. 
Based on group consensus, the most common red flags for ASD in young children were rephrased into 25 items. An overview of the target behaviours is displayed in Table 1. The main objective was that child care workers could easily tick the signs of ASD they observed in a child. Therefore, the items give a general description of the target behaviour, but they also provide sufficient examples of this behavior. A preliminary version of the CESDD was evaluated in five day-care centres across Flanders and the items were adapted based on the feedback of child care workers.

\section{[INSERT TABLE 1 HERE]}

The items were ordered according to the chronological appearance of the targeted behaviours or skills in normal development. This led to three groups of items: items that are red flags for ASD at any age, items that can indicate high risk for ASD in children older than 12 months and items that hold risk for ASD in children from 24 months onwards.

Four items were added regarding the language development of children, based on the practice parameter proposed by Filipek and colleagues (2000) for level one screening: babbling by 12 months, use of single words by 16 months, spontaneous use of 2-word phrases by 24 months and any loss of language skills. Child care workers had four response alternatives for these items: "yes", "no", "I don't know", and "not applicable (the child has not yet reached the intended age)". Not only are language impairments present in most ASD subtypes (Mitchell et al., 2006), language delay is also the most common concern that first prompts parents of children who are later diagnosed with ASD to consult a health care provider (De Giacomo \& Fombonne, 1998). By including language items as well, we also intended to lower the amount of unidentified children with ASD in our screening procedure (i.e. some children who screen negative for ASD but who have the disorder may be detected early on based on further assessment because of delayed language development). 
Finally, child care workers were asked about multilingual upbringing and earlier clinical and medical diagnoses that the child received. Space was included for additional remarks.

A preliminary cut-off score for ASD was set on 2 or more ticked items for children younger than 12 months and 4 or more ticked items for children older than 12 months. This cut-off score was obtained by setting the threshold at the $97^{\text {th }}$ percentile on total ticked signs of ASD (language items are not included) in a pilot study in 11 day-care centres $(n=600)$. These children were also included in the total sample.

\section{Screening Procedure}

A flow-chart of the design of this screening study is displayed in Figure 1. Prior to participation in this study, staff of the day-care centres followed a 3-hour training about recognition of early signs of ASD and how to use the CESDD. This training consisted of four parts. In a first part, the diagnostic criteria of ASD as well as the prevalence of the disorder and the advantages of early identification of children with ASD were discussed. In the second part, early social-communicative skills were discussed: imitation, joint attention and pretend play. An overview of the typical development of these skills was given, illustrated with videos, as well as the impairments in social-communicative skills in children with ASD. The third part of the training consisted of a detailed explanation of each item of the CESDD. The signs were illustrated with video material of typically developing children, children with ASD and children with other developmental disorders. Attention was paid on how to correctly fill out the CESDD: whenever a child is behaving qualitatively different from its peers in a certain domain, the item should be checked. Finally, we gave more information about the further stages of the screening procedure. 
For each participating day-care centre, the person in charge of the coordination of the screening procedure in the centre followed the training (mostly graduate nurses), usually accompanied by some colleagues (child care workers). Day-care centres received a brochure containing all the information given in the training as a reference tool. Child care workers who did not attend the session were trained in filling out the CESDD by the responsible nurses.

Stage 1 - screening for ASD in day-care centres. Child care workers filled out the CESDD for each child in their day-care centre. Parents were informed about the participation of the day-care centre in this study and had the opportunity to refuse that the CESDD was filled out for their child. Each child was given a code so that it could be retraced later on. Child care workers were asked to fill out the CESDD again for screen positive children after a period of approximately three months (if the children were still in the day-care centre).

After processing the filled out checklists, day-care centres were informed about which children had to be followed up. We asked the person responsible for the participation in the study to explain the ticked signs of ASD to the parents of the children who scored above the cut-off for ASD on the CESDD without mentioning ASD or otherwise distressing the parents. To support this conversation to the parents, they could rely on a written scenario provided by the research group. This person also asked the parents to further participate in this study by giving them additional parent-report questionnaires. In addition, all the parents of children who were suspected of having language delay (as measured with the language items) were also asked to fill out the same parent questionnaires. This was not the case for children who only failed the language items and had a multilingual upbringing because a slower language acquisition in those children is more common than in monolingual children (Hoff \& Elledge, 2005). 
Stage 2 - screening for ASD using parent report. Parents of children with language delay or a positive screen for ASD on the CESDD were asked to complete the abridged Dutch version of the MacArthur Communication Development Inventories (N-CDI's korte vormen; Zink, 2003). There are two versions of this inventory: one version is used for children between 8 and 16 months and another version is suitable for children between 16 and 30 months. All parents were also asked to complete the 14-item ESAT (Dietz et al., 2006; Swinkels et al., 2006). Based on the age of the child, parents also received a second screening instrument for ASD: the FYI (Reznick et al., 2007; Watson et al., 2007; Dutch translation by Meirsschaut, Dereu, \& Roeyers, 2006) for children between 11 and 13 months, the M-CHAT (Robins et al., 2001; Dutch translation by Dereu, Meirsschaut, Warreyn \& Roeyers, 2006) for children between 18 and 24 months and the SCQ (Rutter, Bailey, \& Lord, 2003; Dutch translation by Warreyn, Raymaekers, \& Roeyers, 2004) for children older than 24 months.

If children screened positive on at least one screener for ASD and/or had a language delay of at least 4 months and scored below the $10^{\text {th }}$ percentile on both receptive and expressive language, the children were invited with their parents at the university lab for further developmental assessment. Parents of children who screened negative for ASD and showed no signs of a considerable language delay as measured by parent questionnaires, were informed of these test results by mail and did not further participate in the next stages of the screening procedure. However, if children had at least two subsequent positive screens for ASD on the CESDD, they were invited for further assessment. Moreover, if parents had any concerns about the further development of their child, they still could contact us to participate in the developmental assessment.

Stage 3 - Developmental assessment at the university lab. This assessment consisted of an estimate of the general developmental level of the child with the Mullen Scales of Early Learning (MSEL; Mullen, 1995) as well as a semi-standardized observation of the child with 
the Autism Diagnostic Observation Schedule - Generic (ADOS-G; Lord, Rutter, DiLavore, \& Risi, 1999). Sixty children were seen at the university lab. Twelve children showed a typical development and had no clear signs of ASD. These children were not referred for further assessment.

Stage 4 - Referring children for diagnosis. Based on consensus clinical judgment of the research group, 48 children were referred to specialized university based autism clinics or diagnostic centres for developmental disorders across Flanders. After referral, 21 children were diagnosed with non-ASD developmental delay, 20 children were diagnosed with ASD, and another 7 children are highly suspected of having ASD (3 children with a working diagnosis and 4 children of which parents declined the referral).

\section{[INSERT FIGURE 1 HERE]}

\section{Results}

\section{Response Rates for the Different Stages of the Screening Procedure}

Of the total sample of 6808 children, 293 children (4.30\%) screened positive for ASD on the CESDD and 619 children failed the language items (9.09\%). For 146 children with a positive screen for ASD (49.83\%) the CESDD was filled out at least twice. The response rate (RR) for filling out the parent questionnaires was $31.56 \%$ in general. The RR was slightly higher for children who screened positive for ASD on the CESDD (RR $=33.45 \%)$ than for children who only failed the language items $(R R=30.49 \%)$, although this difference was not significant $\left(\chi^{2}(1)=.76, p>.05\right)$. The $\mathrm{RR}$ was $58.33 \%$ for children with at least two subsequent positive screens on the CESDD. Parents completed the questionnaires on average 2.92 months $(S D=3.34)$ after the CESDD was filled out. The children had a mean age of 23.34 months $(S D=6.41$, range $8.20-48.13,60 \%$ boys $)$ when the parent questionnaires were filled out. 
Response rates for further assessment were higher. Of children with at least one positive screen for ASD or suspected language delay on parent questionnaires, $50.59 \%$ was seen for a developmental assessment. Again, the RR for children who screened positive for ASD on the parent questionnaires $(\mathrm{RR}=54.84 \%)$ was higher than the $\mathrm{RR}$ for children with only suspected language delay as measured with the N-CDI's $(\mathrm{RR}=39.13 \%)$, but the difference was not statistically significant $\left(\chi^{2}(1)=1.66, p>.05\right)$. Of children with no signs of developmental problems as measured by parent questionnaires but with at least two positive screens on the CESDD $(n=15), 53.33 \%$ were seen at the university lab. Children were seen on average 2.84 months $(S D=4.38)$ after the parents filled out the questionnaires and 5.89 months $(S D=5.97)$ after the CESDD was filled out. The children had a mean age of 28.08 months $(S D=7.25$, range $13.47-51.40,70 \%$ boys $)$ when they were assessed at the university lab.

\section{Sample Characteristics}

The total scores on the CESDD ranged between 0 and $19(M=0.36 ; S D=1.45)$ for the entire sample of 6808 children. Table 2 shows the mean total scores on the CESDD for the different diagnostic groups. Because the distribution of CESDD total scores was strongly negatively skewed, the Kruskal-Wallis test was used to compare the mean scores on the CESDD for the different diagnostic groups. There was a significant difference between groups, $\chi^{2}(3)=488.58, p<.001$. Pairwise comparison with the Mann Whitney U test showed that only children suspected with ASD and children with ASD did not differ significantly from each other in total score on the CESDD (Table 3). In further analyses, these groups were combined in the group ASD cases.

[INSERT TABLE 2 AND TABLE 3 HERE] 
Table 4 outlines the CESDD total scores and the demographic details of the ASD and the non-ASD group. The proportion of multilingual children was similar for both groups $\left(\chi^{2}(1)\right.$ $=.09, p>.05)$. Children with ASD scored significantly higher on the CESDD than non-ASD cases, Mann-Whitney $U=26813.50, p<.001$. There were significantly more males in the ASD group, $\chi^{2}(1)=5.68, p<.05$. Children with ASD were significantly older than children without the disorder, $t(6806)=6.70, p<.001$.

[INSERT TABLE 4 HERE]

\section{Discrimination between ASD and Non-ASD Cases}

Sensitivity, specificity and likelihood ratios. To evaluate the discriminant power of the CESDD in distinguishing ASD cases from non-ASD cases (only including signs of ASD and not the language items), we performed a receiver operating characteristic (ROC) analysis (Figure 2). The area under the curve was .90 (95\% CI $=0.84-0.97)$, indicating strong discriminant ability.

\section{[INSERT FIGURE 2 HERE]}

At the preliminary cut-off scores of $\geq 2$ signs of ASD in children younger than 12 months and $\geq 4$ signs in children older than 12 months (not including the language items), sensitivity (Se) was .68, specificity (Spec) was .96, positive predictive value (PPV) was .10 and negative predictive value (NPV) was .99 (Table 5). PPV and NPV depend on the prevalence of the disorder. Because of the low prevalence of ASD and the range in prevalence rates reported by different studies, we report here also likelihood ratios which are not dependent on prevalence rates. Positive likelihood ratio (LR+; how much the probability of having ASD increases after a positive screen) was 17.42. This means that a child with ASD is about 17 times more likely to have a positive screen on the CESDD than a child 
without ASD (rates above 10 are considered as good; Akobeng, 2006). The negative likelihood ratio (LR-; how much the propability of having ASD decreases after a negative screen) was .33 . This means that the probability of having a negative test for children with ASD is about one-third of that of those without the disorder (LR- below .10 virtually rule out the chance that a person has ASD; Akobeng, 2006).

Based on the ROC curve, lowering the cut-off to two or more signs of ASD for all children results in an optimal Se and Spec. With this cut-off, Se was raised to .80 at the cost of a lower Spec of .94, PPV was lowered to .07 but NPV remained .99 and +LR and -LR were lowered to respectively 12.98 and .21 (Table 6). Lowering the cut-off to two or more signs for all children results in less false negatives $(n=8)$ but also much more false positive results $(n=419)$.

\section{[INSERT TABLE 5 AND TABLE 6 HERE]}

False negatives and false positives. Using the preliminary cut-off scores and based on currently known diagnoses, there were 13 false negative screens and 265 false positive screens. The group of children who screened false negative did not differ from the group of true positive children in gender or age $\left(\chi^{2}(1)=2.62, p>.05\right.$ and $t(39)=-1.27, p>.05$ respectively).

Children who screened false positive did not differ from true negatives in age $(t(6765)$ $=1.04, \mathrm{p}>.05)$. There were, however, more boys in the false positive group, $\chi^{2}(1)=7.62, p$ $<.01$. There were also more children with a developmental disorder or delay in the false positive group compared to true negatives, $\chi^{2}(1)=359.89, p<.001$.

Item analysis. Chi-square analysis showed that all signs of ASD included in the CESDD were more recognized by child care workers in ASD cases than in non-ASD cases. Odds ratios were calculated to assess which items best predicted ASD. The items with the 
highest odds ratio for ASD were 'use of someone's hand as an instrument', 'lack of following joint attention', 'lack of symbolic play', 'unusual sensory behaviour' and 'lack of enjoyment in social play'. Table 7 shows the odds ratios and the percentage of ASD cases and non-ASD cases for which each sign was recognized.

[INSERT TABLE 7 HERE]

\section{Discussion}

The aim of the present study was to develop a screening instrument for ASD for the general population that can be used within day-care centres. This study is the first prospective screening study that incorporates child care workers' report on signs of ASD in young children. Although some children were already diagnosed with ASD $(n=7)$ or had a working diagnosis of ASD $(n=7)$, another 20 children out of 6808 screened were diagnosed with ASD as a result of this screening procedure. In addition, seven children are suspected of having the disorder based on ADOS-G classification and clinical judgment of our research group $(n=3)$ or received a working diagnosis of ASD and await re-evaluation at diagnostic centres $(n=4)$. This indicates that the procedure used helped to identify children with ASD at a young age.

ROC analysis indicated strong ability of the CESDD in discriminating ASD from non-ASD cases. Using the preliminary cut-off scores, sensitivity was .68 and specificity was .96. Lowering the cut-off score to two or more signs of ASD for children results in a higher sensitivity of .80 but at the cost of more false positives since the specificity decreases to .94. In the current study, the goal was to detect as many children with ASD as possible thus the emphasis was on the sensitivity of the screening. If the sensitivity for ASD is considered more important than the amount of false positives (who may have other 
developmental disorders), we would suggest lowering the cut-off to two signs of ASD in all children. However, one should be cautious in interpreting these results because we did not include all children with only two signs of ASD in further stages of the screening design. Further research will have to shed light on the psychometric properties at the lower cut-off. Also, the discriminant ability of the CESDD may depend on the procedure used, including a training of staff in day-care centres in recognizing early signs of ASD and in how to fill out the CESDD. A complete training package was developed (including video materials and a written scenario of the information given during the training session) which accompanies the screening instrument. Future research should evaluate the discriminant ability of the CESDD filled out by child care workers who followed the training session versus those who received the information from a nurse in their centre.

When we compare these measures of predictive validity with those of other screeners for ASD in young children, the specificity of this screener is high. Although for some screeners the reported sensitivity is higher (e.g. M-CHAT and FYI), they did not calculate the estimated sensitivity for an unselected sample. Instead, they calculated sensitivity and specificity based on cases that were already diagnosed or included high-risk children, thereby increasing the prevalence of ASD (Honda et al., 2009) and thereby possible overestimation of the PPV and NPV. Other screeners that estimated the predictive validity based on a general population study yielded lower sensitivity (e.g. CHAT and ESAT). In this light, the CESDD seems promising to be used in the general population. Moreover, all items were sensitive to ASD. 'Use of someone's hand as an instrument' was the item that could best distinguish ASD from non-ASD cases in our study. It is an early sign often found in home video studies (Gray \& Tonge, 2001). Comparison with other screening studies is, however, impossible because other instruments for young children did not incorporate this item. Also 'lack of following joint attention' was found to have a high odds ratio. Items regarding joint attention were also 
found to be highly discriminative in other screening instruments such as the M-CHAT (Robins et al., 2001). Moreover, home video studies found joint attention to be one of the most important early signs of ASD in infants or toddlers (Mars et al., 1998; Maestro et al., 2001). 'Lack of symbolic play' also had a high discriminative power. Similar items are included in the M-CHAT and ESAT, but could not well discriminate between ASD and nonASD cases (Robins et al., 2001; Swinkels et al., 2006), possibly because the children in those studies were younger. In the CESDD, the item about symbolic play only has to be considered for children older than 24 months. Other items with odds ratios above 35 were 'unusual sensory behaviour' and 'lack of enjoyment in social play'. Similar items in the ESAT were more often recognized in children with ASD than in children with ADHD or typical developing children (Swinkels et al., 2006). However, the ESAT item regarding enjoying social play could not discriminate ASD from non-ASD cases (Dietz et al., 2006). Other studies also found 'response to name' or 'reacts when spoken to' as items of screening instruments with the highest discriminative power in their sample (Dietz et al., 2006; Robins et al., 2001). Although these items could also discriminate between ASD and non-ASD cases in our study, they were not among the items with the highest odds ratios.

The more rare a disease is, the more accurate the screening instrument has to be, since the Bayes theorem states that the chance that a disease is truly present depends on the prevalence of the disease and the properties of the test (Akobeng, 2006). Because of the low prevalence rate of $\mathrm{ASD}$, designing screening instruments to be used in the general population with an acceptable sensitivity is rather difficult. Groen and colleagues (2007) argued that it is better to look at the positive likelihood ratio to evaluate if the screener can contribute to the detection of the disorder rather than looking at the PPV and the NPV, because those depend on the prevalence rate of ASD. The likelihood ratio for the CESDD is good at both proposed cut-off scores. Using the preliminary cut-off scores, the probability that a child has ASD after 
a positive screen on the CESDD increases with 17.42. With the proposed cut-off score of two signs of ASD, the positive likelihood ratio was 12.98. When we compare those ratios with the likelihood ratios of other population screeners, they are very similar to the positive likelihood ratio of the CHAT (+LR = 16; Baird et al., 2000). However, for the ESAT the estimated likelihood ratio based on the prevalence rates reported by Baird and colleagues (2000) is higher $(+\mathrm{LR}=67.3)$. This higher ratio comes however with a lower sensitivity $(\mathrm{Se}=.23$; Groen et al. 2007). So, when a child screens positive on the ESAT, it is very likely that the child had ASD. However, a lot of children with ASD will screen false negative on the ESAT.

The CESDD yielded a large group of children who screened false positive. Comparing the false positive group to the true negatives showed, however, that there were far more children with a developmental disorder or delay in the false positive group. Differentiating autism and developmental delay from developmental delay alone in toddlers can be difficult (see Charman \& Baird, 2002). Therefore, it is commonly found in screening studies that a lot of the false positive children have developmental disorders other than ASD (e.g. Dietz et al., 2006; Robins et al., 2001). A high number of false positive screens was not regarded as a problem in the proposed screening procedure because for these children further assessment is also desirable. The CESDD is used as a Level 1 screener and a positive screen on the CESDD only leads to sending additional screening instruments to the parents and not immediately to more extensive developmental assessment.

There were also a number of missed cases of ASD. Kleinman and colleagues (2008) argued that some high functioning children with ASD might not be detectable by screening instruments until later in childhood. By including children with only language delay in further stages of the screening procedure, we could, however, already detect some false negative cases. Since further assessment was not limited to positive screens for ASD but also included children failing language items, some children who screened negative for ASD on the 
CESDD were also included in further stages of the procedure. This helped us to detect more false negative screens and may have resulted in a better estimate of the sensitivity than studies that only incorporate positive screens in further stages of the procedure (e.g. ESAT). For example, 8 children who scored below the cut-off for ASD on the CESDD were included in further stages of the procedure because they failed a language item and were diagnosed with ASD after referral. It remains, however, possible that we still missed some cases, for example children with Asperger Syndrome. Further follow-up of the children until primary school age could detect these children.

Prevalence estimates of ASD are largely based on samples of children at school age or even older. It is still unknown which percentage of children with ASD shows clear signs of ASD in the first years of life (Dietz et al., 2006). Based on diagnoses reported on the CESDD and diagnoses made after referral, there were 41 cases of ASD or suspected ASD in our sample of 6808 children. This results in an estimated prevalence rate for ASD of 60.22 per 10 000. This rate is similar to the prevalence rate calculated by Baird and colleagues (2000) after a 6-year follow-up study of a population screen using the CHAT. However, more recent attempts to estimate the prevalence of ASD found rates of above $1 \%$. Baird and colleagues (2006) screened a cohort of children aged 9-10 years with a clinical diagnosis of ASD or those judged to be at risk for being an undetected case and estimated the prevalence of ASD to be 116.1 per 10 000. Baron-Cohen and colleagues (2009) used a similar procedure, but also included children who were not at risk for ASD by a school population screening of children between 5 and 9 years. They estimated the prevalence to be 157 per 10000 . However, the children in our sample are much younger. Further follow-up of the total sample will shed light on more possible missed cases in the current study. We hope to get a clearer picture on missed diagnoses in the following years by mailing questionnaires about referral 
for developmental disorders to a subsample of parents and to the leading diagnostic centres for ASD in Flanders.

\section{Limitations}

The main shortcoming of this study was a rather low compliance rate at each stage of the screening procedure. The response rate was the lowest for returning parent questionnaires (31.56\%). We have, however, no insight in how many questionnaires were indeed given to the parents by the day-care centres. Some day-care centres informed us when they did not give the questionnaires to the parents because, for example, in the mean while the child began to speak single words or the behaviour of the child improved and they did not want to unnecessary worry the parents about the development of their child.

The response rate was somewhat higher for further developmental assessment at the university lab (50.59\%). This may have been the result of a more personal approach. We called up parents and gave them an elaborated report on the results of the parent questionnaires and our reasons for inviting them to the university lab. However, almost half of the parents declined this invitation. The reason most of these parents gave was that they did not have any concerns (yet) about the development of their child because he or she was still very young and that they wanted to await his or her further development. Some of these parents did contact us, however, later on. In some cases they started to have concerns about the development of their child when the child left the day-care centre to attend kindergarten. When even more parents will ask for further assessment in the following years, this could still increase the response rate.

Other reasons to decline further assessment were: the child was already seen at another assessment centre, the parents did not want to put their child to the burden of the 
assessment or it was not feasible for the parents to come to the university. Similar reasons were reported by parents in a Dutch screening study (Dietz et al., 2007).

Another shortcoming of the study is the limited demographic information that could be gathered. Parents' education, occupation, ethnicity, ... was only available for the children seen for further assessment. The educational level of the mothers seemed slightly high. However, comparison with the total population of children in day-care centres in Flanders is difficult because of limited available data. Vanpée, Sannen and Hedebouw (2009) showed that especially higher educated mothers use child minding facilities in Flanders. This suggests that the educational level of the mothers in our study is probably consistent with that of mothers of children attending day-care centres in Flanders. It remains, however, possible that lower educated mothers were somewhat more reluctant to participate in the study.

\section{Conclusion}

Screening for ASD in day-care centres can contribute to an early identification of ASD in young children. The CESDD had a better sensitivity than other screeners used in unselected samples and a good specificity. However, screening with the CESDD generated a large number of false positives. It seems very important not to alarm the parents after a positive screen with the CESDD, but simply use the CESDD as an instrument to select a group of high-risk children who could benefit from further assessment. 


\section{References}

Akobeng, A.K. (2006). Understanding diagnostic tests 2: Likelihood ratios, pre- and post-test probabilities and their use in clinical practice. Acta Paediatrica, 96, 487-491.

American Academy of Pediatrics, Committee on Children with Disabilities (2001). Developmental surveillance and screening of infants and young children. Pediatrics, $108,192-195$.

American Psychiatric Association (2000). Diagnostic and statistical manual of mental disorders, $\left(4^{\text {th }}\right.$ ed. - Text Revision). Washington, DC: American Psychiatric Association.

Adrien, J.L., Fauré, M., Perrot, A., Hameury, L., Garreau, B., Barthelemy, C., \& Sauvage, D. (1991). Autism and family home movies: Preliminary findings. Journal of Autism and Developmental Disorders, 21, 43-49.

Adrien, J.L., Lenoir, P., Martineau, J., Perrot, A., Hameury, L., Larmande, C.L, \& Sauvage, D. (1993). Blind ratings of early symptoms of autism based upon family home movies. Journal of the American Academy of Child and Adolescent Psychiatry, 32, 617-626.

Baird, G., Charman, T., Baron-Cohen, S., Cox, A., Swettenham, J., Wheelwright, S, \& Drew, A. (2000). A screening instrument for autism at 18 months of age: A 6 year follow-up study. Journal of the American Academy of Child and Adolescent Psychiatry, 39, 694702.

Baird, G., Simonoff, E., Pickles, A., Chandler, S., Loucas, T., Meldrum, D., \& Charman, T. (2006). Prevalence of disorders of the autism spectrum in a population cohort of children in South Thames: The Special Needs and Autism Project (SNAP). Lancet, $368,210-215$. 
Baranek, G.T. (1999). Autism during infancy: A retrospective video analysis of sensorymotor and social behaviours at 9-12 months of age. Journal of Autism and Developmental Disorders, 29(3), 213-224.

Baron-Cohen, S., Allen, J., \& Gillberg, C. (1992). Can autism be detected at 18 months? The needle, the haystack, and the CHAT. British Journal of Psychiatry, 161, 839-843.

Baron-Cohen, S., Cox., A., Baird, G., Swettenham, J., Nightingale, N., Morgan, K., Drew, A., \& Charman, T. (1996). Psychological markers in the detection of autism in infancy in a large population. British Journal of Psychiatry, 168, 158-163.

Baron-Cohen, S., Scott, F.J., Allison, C., Williams, J., Bolton, P., Matthews, F.E., \& Brayne, C. (2009). Prevalence of autism-spectrum conditions: UK school-based population study. British Journal of Psychiatry, 194, 500-509.

Branson, D., Vigil, D.C., \& Bingham, A. (2008). Community childcare providers' role in the early detection of autism spectrum disorders. Early Childhood Education Journal, 35, 523-530.

Chakrabarti, S., Haubus, C., Dugmore, S., Orgill, G., \& Devine, F. (2005). A model of early detection and diagnosis of autism spectrum disorder in young children. Infants \& Young Children, 18, 200-211.

Charman, T., \& Baird, G. (2002). Practitioner Review: Diagnosis of autism spectrum disorder in 2- and 3-year-old children. Journal of Child Psychology and Psychiatry, 43, 289305.

De Giacomo, A., \& Fombonne, E. (1998). Parental recognition of developmental abnormalities in autism. European Child \& Adolescent Psychiatry, 7, 131-136.

Dereu, M., Meirsschaut, M., Warreyn, P., \& Roeyers, H. (2006). The Modified Checklist for Autism in Toddlers. Dutch translation. Retrieved from Georgia State University, 
Department

of

Psychology

Website:

http://www2.gsu.edu/ psydlr/Diana_L._Robins,_Ph.D._files/M-CHAT_Dutch.pdf.

Dosreis, S., Weiner, C., Johnson, L., \& Newschaffer, C. (2006). Autism spectrum disorder screening and management practices among general pediatric providers. Developmental and Behavioral Pediatrics, 27(2), 88-94.

Dietz C., Swinkels, S.H.N., van Daalen, E., van Engeland, H., \& Buitelaar, J.K. (2006). Screening for autistic spectrum disorder in children aged 14-15 months. II: Population screening with the Early Screening of Autistic Traits Questionnaire (ESAT). Design and general findings. Journal of Autism and Developmental Disorders, 36, 713-722.

Dietz C., Swinkels, S., van Daalen, E., van Engeland, H., \& Buitelaar, J.K. (2007). Parental compliance after screening social development in toddlers. Archives of Pediatrics \& Adolescent Medicine, 161, 363-368.

Dumont-Mathieu, T., \& Fein, D. (2005). Screening for autism in young children: The Modified Checklist for Autism in Toddlers (M-CHAT) and other measures. Mental Retardation and Developmental Disabilities Research Reviews, 11, 253-262.

Eaves, L.C., \& Ho, H.H. (2004). The very early identification of autism: Outcome to age 41/25. Journal of Autism and Developmental Disorders, 34, 367-378.

Eldevik, S., Hastings, R.P., Hughes, J.C., Jahr, E., Eikeseth, S., \& Cross, S. (2009). Metaanalysis of Early Intensive Behavioral Intervention for children with autism. Journal of Clinical Child and Adolescent Psychology, 38, 439-450.

Filipek, P.A., Accardo, P.J., Ashwal, S., Baranek, G.T., Cook, E.H., Dawson, G., Gordon, B., Gravel, J.S., Johnson, C.P., Kallen, R.J., Levy, S.E., Minshew, N.J., Ozonoff, S., Prizant, B.M., Rapin, I., Rogers, S.J., Stone, W.L., Teplin, S.W., Tuchman, R.F., \& Volkmar, F.R. (2000). Practice parameter: screening and diagnosis of autism. Report 
of the quality standards subcommittee of the American Academy of Neurology and the Child Neurology Society. Neurology, 55, 468-479.

Filipek, P.A., Accardo, P.J., Banarek, G.T., Cook, E.H., Dawson, G., Gordon, B., Gravel, J.S., Johnson, C.P., Kallen, R.J., Levy, S.E., Minshew, N.J., Prizant, B.M., Rapin, I., Rogers, S.J., Stone, W.L., Teplin, S., Tuchman, R.F., \& Volkmar, F.R. (1999). The screening and diagnosis of autism spectrum disorders. Journal of Autism and Developmental Disorders, 29, 439-484.

Gillberg, C., Cederlund, M., Lamberg, K., \& Zeijlon, L. (2006). Brief report: "The autism epidemic". The registered prevalence of autism in a Swedish urban area. Journal of Autism and Developmental Disorders, 36, 429-435.

Gillberg, C., Ehlers, S., Schaumann, H., Jakobsson, G., Dahlgren, S.O., Lindblom, R., Bagenholm, A., Tjuus, T., \& Blidner, E. (1990). Autism under age 3 years: A clinical study of 28 cases referred for autistic symptoms in infancy. Journal of Child Psychology and Psychiatry and Allied Disciplines, 31, 921-934.

Gray, K., \& Tonge, B.J. (2001). Are there early features of autism in infants and preschool children? Journal of Paediatrics and Child Health, 37, 221-226.

Groen, W.B., Swinkels, S.H., van der Gaag, R.J., \& Buitelaar, J.K. (2007). Finding effective screening instruments for autism using Bayes theorem. Archives of Pediatrics and Adolescent Medicine, 161, 415-416.

Harrington, J.W., Patrick, P.A., Edwards, K.S., \& Brand, D.A. (2006). Parental beliefs about autism: Implications for the treating physician. Autism, 10, 452-462.

Hoff, E., \& Elledge, C. (2005). Bilingualism as one of many environmental variables that affect language development. In Cohen, J., McAlister, K.T., Rolstad, K., \& MacSwan, $\mathrm{J}$ (Eds.), Proceedings of the 4th International Symposium on Bilingualism. Somerville, MA: Cascadilla Press. 
Honda, H., Shimizu, Y., Nitto, Y., Imai, M., Ozawa, T., Iwasa, M., Shiga, K., \& Hira, T. (2009). Extration and refinement strategy for detection of autism in 18-month-olds: A guarantee of higher sensitivity and specificity in the process of mass screening. Journal of Child Psychology and Psychiatry, 50, 972-981.

Kind \& Gezin (2008). Jaarverslag 2007. Retrieved March 10, 2009, from http://www.kindengezin.be/Images/Jaarverslag07_tcm149-55932.pdf.

Kleinman, J.M., Robins, D.L., Ventola, P.E., Pandey, J., Boorstein, H.C., Esser, E.L., Wilson, L.B., Rosenthal, M.A., Sutera, S., Verbalis, A.D., Barton, M., Hodgson, S., Green, J., Dumont-Mathieu, T., Volkmar, F., Chawarska, K., Klin, A., \& Fein, D. (2008). The Modified Checklist for Autism in Toddlers: A follow-up study investigating the early detection of autism spectrum disorders. Journal of Autism and Developmental Disorders, 38, 827-839.

Lord, C. (1995). Follow-up of two-year-olds referred for possible autism. Journal of Child Psychology and Psychiatry and Allied Disciplines, 36, 1365-1382.

Lord, C., Rutter, M., DiLavore, P., \& Risi, S. (1999). Autism Diagnostic Observation Schedule: Manual. Los Angeles: Western Psychological Services.

Mars, A.E., Mauk, J.E., \& Dorwick, P.W. (1998). Symptoms of pervasive developmental disorders as observed in prediagnostic home videos of infants and toddlers. The Journal of Pediatrics, 132, 500-504.

Maestro, S., Casella, C., Milone, A., Muratori, F., \& Palacio-Espasa, F. (1999). Study of the onset of autism through home movies. Psychopathology, 32, 292-300.

Maestro, S., Muratori, F., Barbieri, F., Casella, C., Cattaneo, V., Cavallaro, M.C., Cesari, A., Milone, A., Rizzo, L., Viglione, V., Stern, D.D., Palacio-Espasa, F. (2001). Early behavioural development in autistic children: The first 2 years of life through home movies. Psychopathology, 34, 147-152. 
Mitchell, S., Brian, J, Zwaigenbaum, L., Roberts, W., Szatmari, P., Smith, I., \& Bryson, S. (2006). Early language and communication development of infants later diagnosed with autism spectrum disorder. Developmental and Behavioral Pediatrics, 27(2), 6978.

Mullen, E.M. (1995). Mullen Scales of Early Learning. Circle Pines MC: American Guidance Service.

Osterling, J., \& Dawson, G. (1994). Early recognition of children with autism: A study of first birthday home videotapes. Journal of Autism and Developmental Disorders, 24, 247-257.

Osterling, J.A., Dawson, G., \& Munson, J.A. (2002). Early recognition of 1-year-old infants with autism spectrum disorder versus mental retardation. Development and Psychopathology, 14, 239-251.

Renty, J., \& Roeyers, H. (2006). Satisfaction with formal support and education for children with autism spectrum disorder: The voices of the parents. Child: Care, Health, \& Development, 32, 371-385.

Reznick, J.S., Baranek, G.T., Reavis, S., Watson, L.R., \& Crais, E.R. (2007). A parent-report instrument for identifying one-year-olds at risk for an eventual diagnosis of autism: The First Year Inventory. Journal of Autism and Developmental Disorders, 37, 16911710.

Robins, D.L., Fein, D., Barton, M.L., \& Green, J.A. (2001). The Modified Checklist for Autism in Toddlers: An initial study investigating the early detection of autism and pervasive developmental disorders. Journal of Autism and Developmental Disorders, $31,131-144$.

Rutter, M., Bailey, A., \& Lord, C. (2003). Social Communication Questionnaire (SCQ). Los Angeles: Western Psychological Services. 
Stone, W.L., Lee, E.B., Ashford, L., Brisie, J., Hepburn, S.L., Coonrod, E.E., \& Weiss, B.H. (1999). Can autism be diagnosed accurately in children under 3 years? Journal of Child Psychology and Psychiatry and Allied Disciplines, 40, 219-226.

Swinkels, S.H.N., Dietz, C., van Daalen, E., Kerkhof, I.H.G.M., van Engeland, H., \& Buitelaar, J.K. (2006). Screening for autistic spectrum in children aged 14 to 15 months. I: The development of the Early Screening of Autistic Traits Questionnaire (ESAT). Journal of Autism and Developmental Disorders, 36, 723-732.

Vanpée, K., Sannen, L., \& Hedebouw, G. (2009). Child care in Flanders. Use, choice of child care type and evaluation by parents. Retvrieved December 9, 2009, from http://www.kindengezin.be/Images/rapport_child_care_tcm149-5626.doc.

Warreyn, P., Raymaekers, R., \& Roeyers, H. (2004). Handleiding Vragenlijst Sociale Communicatie. Destelbergen: SIG vzw.

Watson, L.R., Baranek, G.T., Crais, E.R., Reznick, J.S., Dykstra, J., \& Perryman, T. (2007). The First Year Inventory: Retrospective parent responses to a questionnaire designed to identify one-year-olds at risk for autism. Journal of Autism and Developmental Disorders, 37, 49-61.

Werner, E., Dawson, G., Osterling, J., \& Dinno, N. (2000). Brief report: Recognition of autism spectrum disorder before one year of age: A retrospective study based on home videotapes. Journal of Autism and Developmental Disorders, 30, 157-162.

Wetherby, A.M., Woods, J., Allen, L., Cleary, J., Dickinson, H., \& Lord, C. (2004). Early indicators of autism spectrum disorders in the second year of life. Journal of Autism and Developmental Disorders, 34, 473-493.

Wiggins, L.D., Baio, J., \& Rice, C. (2006). Examination of the time between first evaluation and first autism spectrum diagnosis in a population-based sample. Developmental and Behavioral Pediatrics, 27(2), 79-87. 
Wimpory, D.C., Hobson, R.P., Williams, J.M.G., \& Nash, S. (2000). Are infants with autism socially engaged? A study of recent retrospective parental reports. Journal of Autism and Developmental Disorders, 30, 525-536.

Zink, I. (2003). N-CDI's: korte vormen. Leuven: Acco.

Zwaigenbaum, L., Bryson, S., Rogers, T., Roberts, W., Brian, J., \& Szatmari, P. (2005). Behavioral manifestations of autism in the first year of life. International Journal of Developmental Neuroscience, 23(2-3), 143-152. 


\section{Author Note}

Mieke Dereu, Petra Warreyn, Ruth Raymaekers, Mieke Meirsschaut, Griet Pattyn, Inge Schietecatte, and Herbert Roeyers, Research Group Developmental Disorders, Department of Experimental Clinical and Health Psychology, Ghent University.

Acknowledgments: Partial funding for this research was provided by support from Steunpunt ExpertiseNetwerken and Vlaamse Vereniging voor Autisme.

Correspondence should be addressed to Mieke Dereu, Ghent University, Department of Experimental Clinical and Health Psychology, Henri Dunantlaan 2, B-9000 Ghent, Belgium. E-mail: mieke.dereu@ugent.be. 
Table 1

Target behaviours of the CESDD

\section{Children between 0 and 36 months:}

Lack of eye contact.

Abnormal eye contact.

Lack of appropriate response to name being called.

Seems to be deaf.

Lack of social smile.

Lack of exploration/passivity.

Doesn't like being touched or cuddled.

Presence of stereotyped behaviour.

Presence of unusual sensory behaviour.

Lack of varied manipulative play.

Lack of shared enjoyment in social play like peek-a-boo.

Lack of imitation.

\section{Children between 12 and 36 months:}

Lack of gestures.

Prefers to be alone.

Lack of point following and/or lack of spontaneously gaze following.

Lack of pointing to indicate interest in objects/persons/events.

Lack of showing objects to indicate interest in it.

Easily frustrated by changes and/or exaggerated reaction to a small source of frustration.

Lack of facial expressions during activities/interactions.

Lack of functional play.

Lack of anticipation of being picked up.

Presence of unusual postures.

Use of someone's hand as an instrument to obtain a desired object.

\section{Children between 24 and 36 months:}

An unusual interest in certain objects, in moving objects, or in parts of objects; lining up objects; let objects twirl or mouthing.

Lack of symbolic play. 
Table 2

Mean scores on the CESDD

\begin{tabular}{lcccc}
\hline Diagnosis & $n$ & $M$ & $S D$ & Range \\
\hline TD & 6706 & 0.29 & 1.18 & $0-19$ \\
DD & 61 & 4.16 & 4.51 & $0-19$ \\
SASD & 14 & 7.00 & 4.47 & $0-15$ \\
ASD & 27 & 6.81 & 5.64 & $0-17$ \\
\hline
\end{tabular}

$\overline{\text { Note: }}$ TD = typical development; DD = developmental delay; sASD = highly suspected of Autism Spectrum Disorder; ASD = Autism Spectrum Disorder. 
Table 3

Mann-Whitney U test for pairwise comparison of total scores for different diagnostic groups

\begin{tabular}{|c|c|c|c|c|}
\hline & TD & $\overline{\mathrm{DD}}$ & sASD & $\overline{A S D}$ \\
\hline \multicolumn{5}{|l|}{ TD } \\
\hline DD & $73997.50 * *$ & & & \\
\hline sASD & $8114.00 * *$ & $262.00 *$ & & \\
\hline ASD & $17849.00 * *$ & $588.50 *$ & 179 & \\
\hline
\end{tabular}

$\overline{\text { Note. }}$ TD = typical development; DD = developmental delay; sASD = highly suspected of Autism Spectrum Disorder; ASD = Autism Spectrum Disorder.

$* p<.05 ; * * p<.001$. 
Table 4

Mean scores on the CESDD and sample demographics of ASD versus non-ASD cases

\begin{tabular}{llllll}
\hline Sample & $N$ & Mean score & Language & Gender & Mean age \\
& & on the & $(\%$ multi- & $(\%$ males $)$ & $($ months $)(S D)$ \\
& & CESDD $(S D)$ & lingual) & & \\
& 6808 & $0.36(1.45)$ & $10.75 \%$ & $52.19 \%$ & $16.70(8.19)$ \\
Total & 41 & $6.88(5.22)$ & $12.20 \%$ & $70.73 \%$ & $25.21(7.32)$ \\
ASD & 6767 & $0.32(1.30)$ & $10.74 \%$ & $52.08 \%$ & $16.64(8.17)$ \\
\hline
\end{tabular}


Table 5

Cross tabulation for ASD versus non-ASD cases and the preliminary cut-off scores

\begin{tabular}{lccc}
\hline & Non-ASD & ASD & Total \\
\hline Neg screen & 6502 & 13 & 6515 \\
Pos screen & 265 & 28 & 293 \\
Total & 6767 & 41 & 6808 \\
\hline
\end{tabular}


Table 6

Cross tabulation for ASD versus non-ASD cases and the cut-off score of two signs of ASD

\begin{tabular}{lccc}
\hline & Non-ASD & ASD & Total \\
\hline Neg screen & 6348 & 8 & 6356 \\
Pos screen & 419 & 33 & 452 \\
Total & 6767 & 41 & 6808 \\
\hline
\end{tabular}


Table 7

Percentage of ASD and non-ASD cases with CESDD-items ticked

\begin{tabular}{|c|c|c|c|c|c|}
\hline & Item & Non-ASD & ASD & Odds ratio & $95 \% \mathrm{CI}$ \\
\hline \multirow{12}{*}{$\begin{array}{l}N=6808 \\
\text { - Non-ASD }(n=6767) \\
\text { - ASD }(n=41)\end{array}$} & Unusual sensory behaviour & $0.5 \%$ & $17.1 \%$ & $39.600 *$ & $16.447-95.346$ \\
\hline & Lack of enjoyment in social play & $0.7 \%$ & $22.0 \%$ & $38.560 *$ & $17.481-85.057$ \\
\hline & Lack of social smile & $1.7 \%$ & $36.6 \%$ & $34.281 *$ & $17.676-66.483$ \\
\hline & Seems to be deaf & $0.3 \%$ & $9.8 \%$ & $31.699 *$ & $10.448-96.173$ \\
\hline & Lack of imitation & $3.0 \%$ & $43.9 \%$ & $25.561 *$ & $13.579-48.117$ \\
\hline & Lack of varied manipulative play & $1.4 \%$ & $26.8 \%$ & $25.480 *$ & $12.407-52.326$ \\
\hline & Stereotyped behaviour & $1.6 \%$ & $29.3 \%$ & $24.813^{*}$ & $12.341-49.887$ \\
\hline & Doesn't like being touched or cuddled & $1.0 \%$ & $19.5 \%$ & $23.533 *$ & $10.490-52.793$ \\
\hline & No response to name & $1.4 \%$ & $22.0 \%$ & $19.966^{*}$ & $9.272-42.993$ \\
\hline & Abnormal eye contact & $1.4 \%$ & $22.0 \%$ & $19.544 *$ & $9.081-42.061$ \\
\hline & Lack of eye contact & $1.3 \%$ & $19.5 \%$ & $18.614^{*}$ & $8.357-41.460$ \\
\hline & Limited activity & $2.1 \%$ & $24.4 \%$ & $15.159 *$ & $7.290-31.521$ \\
\hline & Use of someone's hand as an instrument & $0.6 \%$ & $23.1 \%$ & $51.700 *$ & $22.184-120.488$ \\
\hline & Lack of following joint attention & $0.9 \%$ & $30.8 \%$ & $49.526 *$ & $23.322-105.171$ \\
\hline & Lack of functional play & $2.0 \%$ & $41.0 \%$ & $33.756^{*}$ & $17.210-66.207$ \\
\hline & Lack of showing & $3.7 \%$ & $56.4 \%$ & $33.664 *$ & $17.520-64.682$ \\
\hline$N=4199$ & Unusual postures & $0.9 \%$ & $17.9 \%$ & $24.376 *$ & $10.115-58.740$ \\
\hline - Non-ASD $(n=4160)$ & Lack of anticipation of being picked up & $1.3 \%$ & $23.1 \%$ & $23.247 *$ & $10.523-51.359$ \\
\hline \multirow[t]{5}{*}{$-\operatorname{ASD}(n=39)$} & Lack of pointing to share interest & $2.9 \%$ & $41.0 \%$ & $23.025 *$ & $11.865-44.682$ \\
\hline & Lack of gestures & $2.4 \%$ & $33.3 \%$ & $20.724 *$ & $10.340-41.537$ \\
\hline & Prefers being alone & $2.5 \%$ & $33.3 \%$ & $19.892 *$ & $9.936-39.824$ \\
\hline & Easily frustrated & $5.0 \%$ & $41.0 \%$ & $13.151 *$ & $6.844-25.268$ \\
\hline & Lack of facial expressions & $2.0 \%$ & $20.5 \%$ & $12.676^{*}$ & $5.656-28.411$ \\
\hline$N=1629$ & Lack of symbolic play & $1.8 \%$ & $46.2 \%$ & $46.463^{*}$ & $19.779-109.149$ \\
\hline $\begin{array}{l}\text { - Non-ASD }(n=1603) \\
\text { - ASD }(n=26)\end{array}$ & Unusual interest or stereotyped play & $1.6 \%$ & $34.6 \%$ & $32.111 *$ & $13.106-78.672$ \\
\hline
\end{tabular}

$* p<.001$. 
Figure Captions

Figure 1. Screening design

Figure 2. ROC curve for CESDD discriminating ASD versus non-ASD cases 


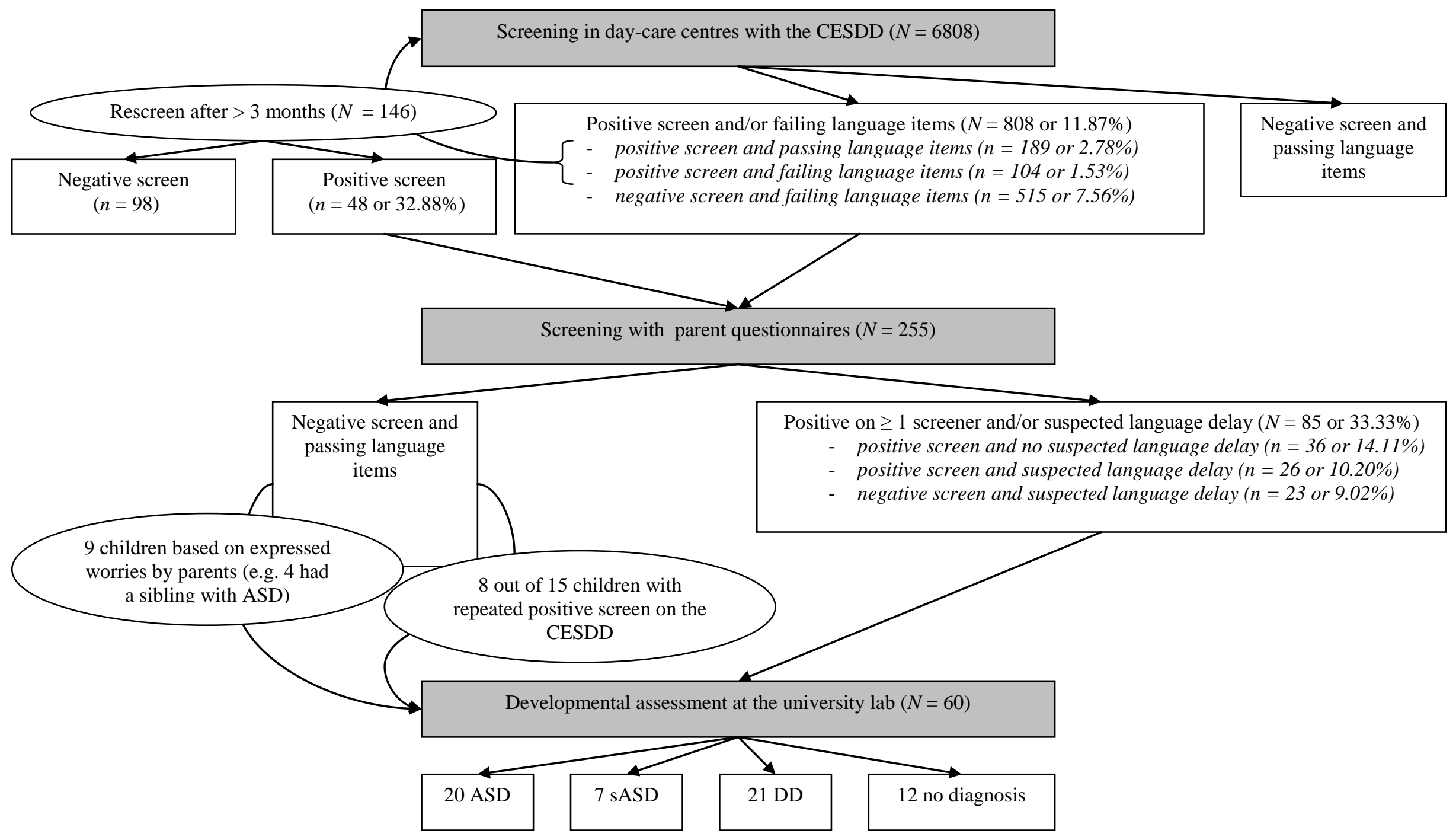

Note. $\mathrm{DD}=$ developmental delay; $\mathrm{sASD}=$ highly suspected of Autism Spectrum Disorder; ASD = Autism Spectrum Disorder. 
ROC Curve for ASD

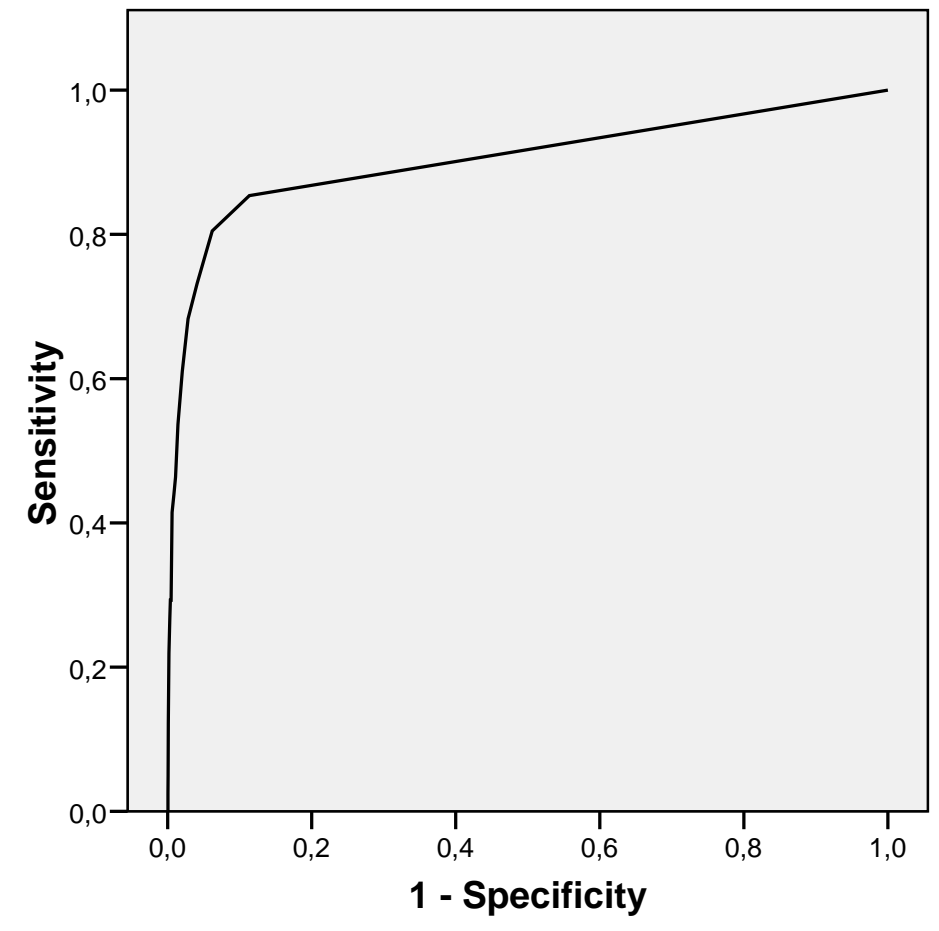

